\title{
Anemia associated with chronic heart failure: current concepts
}

\author{
This article was published in the following Dove Press journal: \\ Clinical Interventions in Aging \\ I February 2013 \\ Number of times this article has been viewed
}

\begin{abstract}
Ravish Shah
Anil K Agarwal

Division of Nephrology, The Ohio State University, Columbus, Ohio, USA
\end{abstract}

Video abstract

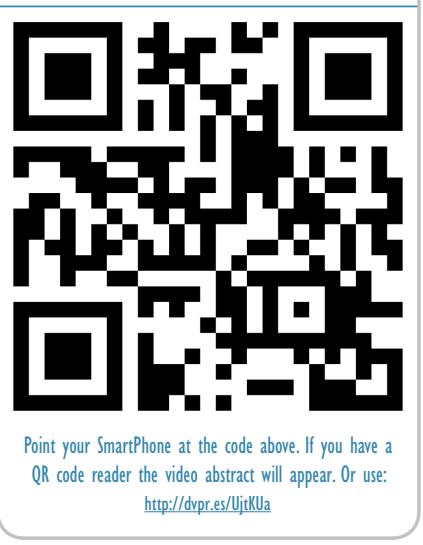

Correspondence: Anil K Agarwal Division of Nephrology, 395 West 12th Avenue, Ground Floor, Columbus, $\mathrm{OH} 43210$, USA

Tel +l 6142934997

Fax +l 6142933073

Email anil.agarwal@osumc.edu
Abstract: Anemia is a frequent comorbidity of heart failure and is associated with poor outcomes. Anemia in heart failure is considered to develop due to a complex interaction of iron deficiency, kidney disease, and cytokine production, although micronutrient insufficiency and blood loss may contribute. Currently, treatment of anemia of heart failure lacks clear targets and specific therapy is not defined. Intravenous iron use has been shown to benefit anemic as well as nonanemic patients with heart failure. Treatment with erythropoietin-stimulating agents has been considered alone or in combination with iron, but robust evidence to dictate clear guidelines is not currently available. Available and emerging new agents in the treatment of anemia of heart failure will need to be tested in randomized, controlled studies.

Keywords: anemia, heart failure, chronic kidney disease, elderly population

\section{Background}

Anemia is common in patients with heart failure, and is a multifactorial and multidimensional problem. ${ }^{1}$ There has been increasing appreciation of the significance of anemia in the pathophysiology, treatment, and prognosis of heart failure. Once considered a downstream complication of heart failure, anemia is now emerging as a crucial and potentially modifiable factor in the overall treatment strategy for patients with chronic heart failure. ${ }^{2}$

\section{Definition}

The true frequency of anemia in patients with heart failure (HF) is not only influenced by the definition used, but also differs according to the patient population and demographics in which anemia is being assessed. Unfortunately, the precise cutoff to define anemia in heart failure has mostly been arbitrary, and there is no consensus about definition of anemia specific to patients with heart failure. Although an historical definition of anemia was put forward by the World Health Organization (WHO), such a definition has not been subjected to rigorous clinical validation, particularly in the setting of heart failure. ${ }^{3,4}$ Considerable variability exists in defining anemia, particularly in the setting of chronic kidney disease (CKD), which often coexists with heart failure, as described in Table $1 .^{5-7}$ Moreover, the threshold hemoglobin level at which anemia treatment should be initiated is an even more complex and controversial clinical question.

\section{Prevalence}

Although the reports of prevalence of anemia vary widely, it is unequivocal that anemia is prevalent in patients with heart failure regardless of the clinical setting. 
Table I Definitions of anemia proposed by various authorities

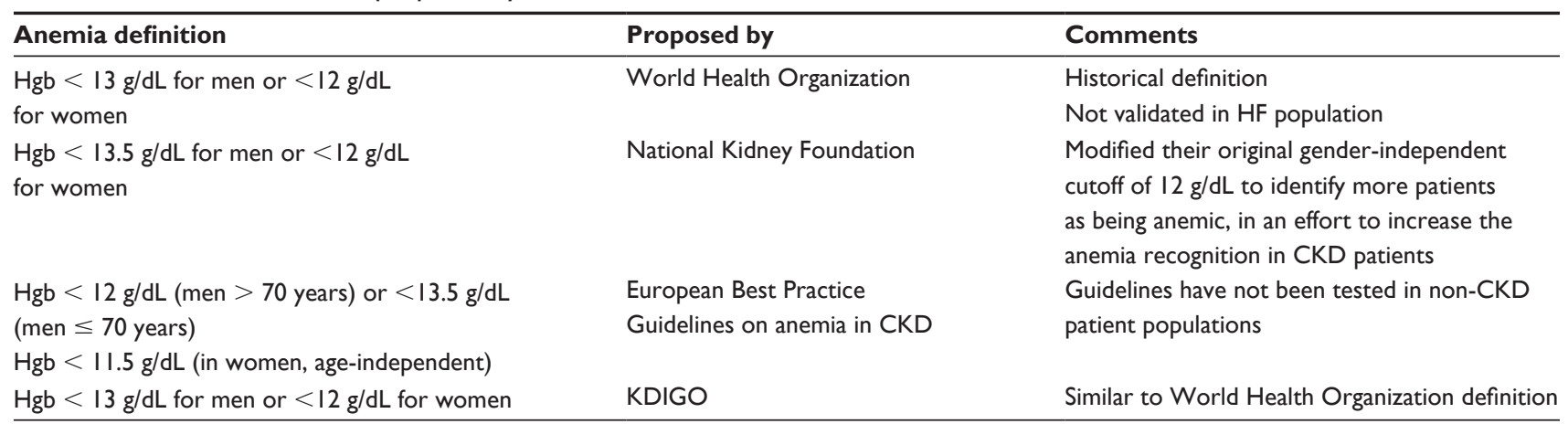

Abbreviations: CKD, chronic kidney disease; HF, heart failure; Hgb, hemoglobin; KDIGO, Kidney Disease: Improving Global Outcomes.

The prevalence of anemia was reported to be $37.2 \%$ in a recent meta-analysis of a total of 153,180 patients with heart failure across 34 published studies over a seven-year period (2001-2007). ${ }^{8}$ This is consistent with the findings from the prospective STAMINA-HFP (Study of Anemia in a Heart Failure Population) registry, which identified a prevalence of $34 \%$ in a cohort of 1076 outpatients with chronic heart failure using the WHO definition of anemia. ${ }^{9}$ A recent Canadian study of a population-based cohort of 12,065 patients with new-onset heart failure from hospital discharges identified a prevalence of anemia of $17 \%$. In this study, more than half of the patients (58\%) were classified as having anemia of chronic disease based on International Classification of Diseases, Ninth Revision (ICD-9) coding. ${ }^{10}$ As might be expected, in addition to variations in definitions, the different practice settings have different mechanisms and different prevalence rates of anemia. For example, those patients in acute decompensated states likely experience more dilutional anemia simply due to hypervolemia. Overall, the prevalence of anemia varies widely, ranging from $14 \%$ to $56 \%$ in outpatient registries to $14 \%$ to $61 \%$ in hospitalized patients. ${ }^{2,11}$

\section{Incidence}

Anemia and CKD commonly coexist in patients HF. However, patients with significant anemia or advanced CKD are often excluded from the heart failure clinical trials, limiting generalizability of the study results in this subgroup of patients who are at the highest risk and also most likely to benefit from the treatment of anemia. ${ }^{2}$ The SOLVD (Studies of Left Ventricular Dysfunction) trial found a 9.6\% incidence of new-onset anemia at one year. ${ }^{2}$ Recent large trials, such as COMET (Carvedilol or Metoprolol European Trial) and Val-HeFT (Valsartan in Heart Failure Trial) observed higher one-year incidence rates of $14.2 \%$ and $16.9 \%$, respectively. ${ }^{12,13}$ However, the volume status of the patients at baseline is not always well characterized; some degree of dilutional anemia can occur as a result of hypervolemia and is likely to resolve with improvement in the volume status. ${ }^{14}$ Nonetheless, patients with less impaired cardiac function (left ventricular ejection fraction $>30 \%$, B-type natriuretic peptide $<325 \mathrm{pg} / \mathrm{mL}$ ), relatively normal renal function, and without diabetes mellitus, were more likely to have resolution of their anemia over time. ${ }^{2}$

\section{Mechanisms of anemia in heart failure}

As previously indicated, anemia in heart failure is multifactorial.

\section{Iron deficiency}

The prevalence of iron deficiency has been reported to range from $5 \%$ to $21 \%$ in patients with heart failure. Although, in one study up to $73 \%$ of HF patients were found to have depleted bone marrow iron stores, microcytic anemia was observed only in a fraction of those patients. ${ }^{15} \mathrm{~A}$ direct link between congestive heart failure (CHF) and iron deficiency anemia (IDA) has yet to be discovered, particularly in the absence of comorbid conditions, such as severe right ventricular failure with gastrointestinal edema resulting in poor iron absorption or advanced CKD associated with uremic gastritis. Cytokine activation and inflammation associated with heart failure may be yet another cause of anemia due to poor iron utilization. Most investigators agree that hematinic abnormalities are infrequent in patients with heart failure. ${ }^{16,17}$ However, subclinical iron deficiency can result in impaired aerobic capacity independent of anemia.

\section{Role of inflammation}

A commonly entertained but still mostly unproven mechanism is that anemia in heart failure resembles anemia of chronic disease as evidenced by iron acquisition in the 
reticuloendothelial system. ${ }^{18}$ Plasma levels of tumor necrosis factor-alpha (TNF- $\alpha$ ), interleukin-1, and interleukin-6 are elevated in severely symptomatic patients with heart failure, promoting iron storage by the reticuloendothelial system, likely contributing to the anemia. ${ }^{19,20}$ Inflammatory cytokines, such as interleukin- 6 and TNF- $\alpha$, have been shown to inhibit renal production of erythropoietin by activating GATA 2 binding protein and nuclear factor-kB. ${ }^{17}$ High levels of TNF- $\alpha$ and interleukin-6 have a tendency to inhibit proliferation of bone marrow erythroid progenitor cells. Hepcidin, an acute phase reactant with intrinsic antimicrobial activity, is synthesized in the liver. Of the two known isoforms, hepcidin-25 plays a key role in iron homeostasis, while the role of hepcidin-20, which lacks the five amino acid sequence, thought to be crucial for iron regulation, remains unclear. ${ }^{20}$ Hepatic production of hepcidin is stimulated by interleukin-6, resulting in impaired duodenal iron absorption and downregulation of ferroportin expression, preventing release of stored iron. ${ }^{20}$ Anemia of chronic disease and iron deficiency anemia may coexist in patients with congestive heart failure, complicating the clinical picture, and one may need to measure soluble transferrin receptors and ferritin levels for further delineation. ${ }^{18}$ Anemia of chronic disease rather than iron deficiency anemia is far more frequent in patients with heart failure. ${ }^{21}$ Although the precise mechanisms are incompletely understood, both inflammatory stress and impaired iron metabolism appear to play a role. ${ }^{22}$

Anemia in an aging population can be further complicated by other factors, including reduced stem cell production, low hematopoietic growth factor production, and altered sensitivity to hematopoietic cytokines. ${ }^{23}$ In addition, higher levels of proinflammatory cytokines, such as interleukin-1, TNF- $\alpha$, and interleukin- 6 , are noted in a variety of diseases unique to the elderly population, ie, atherosclerosis, diabetes mellitus, and cancer. ${ }^{23}$ Although, there are some data to suggest that carnitine supplementation leads to improvement in anemia and possible reduction in erythropoietin-stimulating agent (ESA) requirements in patients with end-stage renal disease on hemodialysis, the role of carnitine supplementation is yet to be explored in anemic patients with heart failure. ${ }^{24}$

\section{Erythropoietin production and resistance}

Erythropoietin, a highly glycosylated (40\% of total molecular weight) proerythrocytic hormone with a half-life of around 5 hours, is a crucial component of the hematopoietic system in regulation of red blood cell production, and subsequently affects tissue oxygen delivery. Specialized peritubular fibroblasts located in the cortex and outer medulla are responsible for the majority of renal erythropoietin production (90\%), while the remainder is synthesized in the liver. ${ }^{21}$ Renal hypoxia is the main stimulus for erythropoietin production, resulting in an exponential increase in the number of erythropoietinproducing cells. ${ }^{25}$ Not surprisingly, this response is blunted in patients with chronic kidney disease. Renal blood flow is relatively well maintained in patients with heart failure until the late stages, especially in patients on angiotensin-converting enzyme inhibitors. Renal hypoxia in this setting is more likely due to the presence of local arteriovenous shunts in the intrarenal circulation, resulting in a substantial reduction in oxygen tension and stimulation of erythropoietin production. Defective erythropoietin production was demonstrated in more than $90 \%$ of patients with heart failure and laboratory evidence of anemia of chronic disease. ${ }^{25}$ In contrast with earlier studies, more recent studies have failed to demonstrate a significant correlation between erythropoietin production and effective renal plasma flow in the setting of heart failure. ${ }^{26} \mathrm{~A}$ weak but significant correlation between erythropoietin production and estimated glomerular filtration rate indicates that renal dysfunction plays a role in the blunted production of erythropoietin in anemic patients with heart failure. ${ }^{26}$

\section{Renin-angiotensin system}

Treatment with angiotensin-converting enzyme (ACE) inhibitors and angiotensin receptor blockers inhibits erythropoiesis, as evidenced by a decrease in hemoglobin concentration up to $0.3 \mathrm{~g} / \mathrm{dL} .{ }^{27}$ This is mainly due to antagonism of a decrease in angiotensin II-medicated renal hypoxia which in turn triggers erythropoietin production. Notably, angiotensin II also stimulates production of erythropoietic cells directly by the bone marrow. ${ }^{21}$ In addition, the amino terminal catalytic domain of the ACE degrades the hematopoiesis inhibitor, $\mathrm{N}$-acetyl-seryl-aspartyl-lysyl-proline (Ac-SDKP). Elevated levels of Ac-SDKP result in inhibition of hematopoiesis and lead to a fall in hemoglobin concentration in HF patients with on ACE inhibitor therapy. ${ }^{28}$ However, experimental data in various knockout mouse models involving different angiotensin-converting enzyme components fail to support this theory. ${ }^{29}$ Figure 1 illustrates the complex inter-relationships of all these mechanisms in the setting of heart failure. ${ }^{30}$

\section{Clinical characteristics associated with anemia in heart failure Age}

Although the incidence varies widely depending on the definition used, it is estimated that almost $11 \%$ of men and $10 \%$ of women over the age of 65 years in the US are 


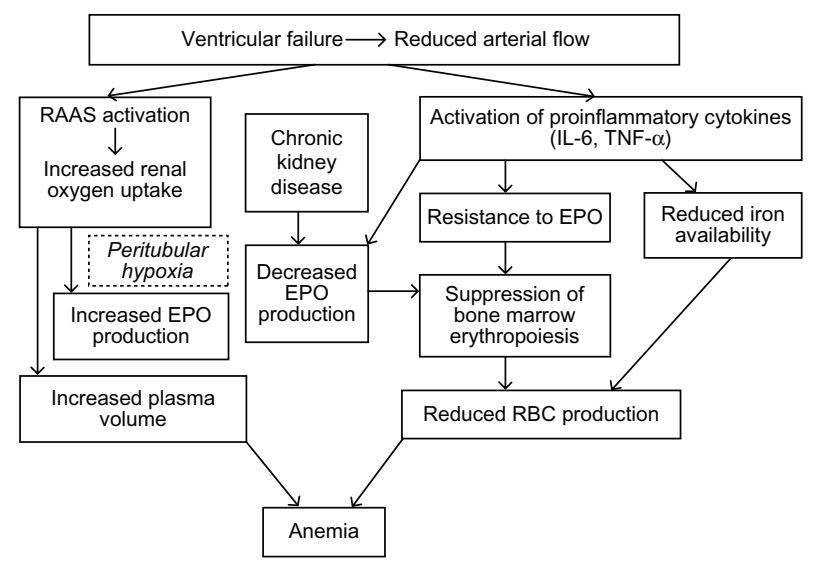

Figure I Overlapping mechanisms of anemia in heart failure. (C) Hindawi Publishing Corporation. Adapted with permission from Alexandrakis MG, Tsirakis G. International Scholarly Research Network. Hematology. 2012.30 Abbreviations: EPO, epoetin; IL-6, interleukin-6; RAAS, renin-angiotensinaldosterone system; TNF- $\alpha$, tumor necrosis alpha.

anemic. ${ }^{31,32}$ Moreover, this proportion doubles in the elderly population over the age of 85 years. ${ }^{32}$ Anemia in the elderly is associated with numerous poor outcomes, including a progressive decline in functional capacity, increased vulnerability to falling, and impaired cognition. ${ }^{32}$ Elderly patients with anemia often have significant comorbidities, including heart failure and chronic kidney disease. ${ }^{32}$ Studies have also demonstrated that, overall, patients with heart failure and anemia tend to be older than their nonanemic counterparts. ${ }^{33}$ In contrast with anemia in younger people, anemia in elderly persons is more common in men than in women. ${ }^{34}$ Anemia is also approximately three times more prevalent in elderly African-Americans than among non-Hispanic Caucasians. ${ }^{34}$ Nutritional deficiencies account for approximately 34\% of cases of anemia in the elderly, while anemia of chronic disease, with or without renal insufficiency, accounts for an additional 33\%. ${ }^{35}$ Studies have shown that, compared with nonanemic patients, the 5-year mortality of anemic men and women is 2.4 and 1.6 times greater, respectively. ${ }^{31}$ It should be noted that the increased mortality associated with anemia remains unchanged even after adjusting for pre-existing comorbid conditions. ${ }^{30}$ Thus, the presence of anemia has important prognostic implications in older patients, irrespective of heart failure.

\section{Female gender}

The data supporting the higher risk for anemia in women compared with men with heart failure are scarce, in part because of the overwhelming male predominance in most CHF studies. For example, a recent study of anemia in ambulatory patients with $\mathrm{CHF}$ reported a $64 \%$ male predominance. ${ }^{35}$ However, anemia studies in HF patients have noted that the percentage of women steadily increases as the severity of anemia increases..$^{36,37}$

\section{Chronic kidney disease}

Chronic kidney disease (as defined by a glomerular filtration rate $<60 \mathrm{~mL} / \mathrm{min} / 1.73 \mathrm{~m}^{2}$ or the presence of other markers of kidney damage, such as structural or functional abnormalities with or without decreased glomerular filtration rate) and anemia are among the most frequent comorbid conditions in patients with CHF. ${ }^{5,36,37}$ Not surprisingly, studies have noted that anemia is more prevalent in patients with $\mathrm{CHF}$ and $\mathrm{CKD}$ than in patients with $\mathrm{CHF}$ alone, in both ambulatory and hospitalized settings. ${ }^{31,36,38}$ The fall in hemoglobin concentration has been repeatedly shown to parallel closely that of estimated glomerular filtration rate in large congestive heart failure registries, and provides strong indirect evidence that the kidney plays a major role in the pathogenesis of anemia in HF patients..$^{33,38}$

\section{Diagnosis of iron deficiency anemia in patients with heart failure}

Anemia with low iron reserve on the basis of low transferrin saturation and relatively higher levels of ferritin identifies the two most common causes of anemia in patients with heart failure, namely anemia of chronic disease (AOCD) and iron deficiency anemia (IDA).$^{39}$ AOCD is identified by reduced concentrations of serum iron, transferrin, and total iron binding capacity along with normal or elevated ferritin (Table 2). ${ }^{25,40}$ However, limited data exist to guide treatment of anemic patients in an inflammatory milieu (eg, hemodialysis, heart failure) with high ferritin levels and low transferrin saturation. Iron-responsive anemia has been suggested to exist in patients on hemodialysis with a hemoglobin level $\leq 12 \mathrm{~g} / \mathrm{dL}$, transferrin saturation $<20 \%$, and any ferritin level $<500 \mu \mathrm{g} / \mathrm{L}$, considering that ferritin levels may be elevated because of an inflammatory milieu, while higher levels $(>500 \mu \mathrm{g} / \mathrm{L})$ could potentially indicate a risk of iron intoxication when more iron is administered. The DRIVE (Dialysis Patients' Response to IV Iron with Elevated Ferritin) study demonstrated that administration of ferric gluconate for 8 consecutive hemodialysis sessions to anemic patients with high ferritin levels was safe and effective in correcting the anemia, despite a further increase in ferritin levels $(P=0.028){ }^{41}$

\section{Treatment approaches to anemia in heart failure}

The potential benefits of treating anemia in patients with heart failure include improved oxygen delivery, attenuation 
Table 2 Laboratory findings in ferropenic anemia, chronic disease anemia, and HF-related anemia with iron deficiency ${ }^{40}$

\begin{tabular}{lllll}
\hline Type of anemia & $\begin{array}{l}\text { Soluble transferrin } \\
\text { receptors }\end{array}$ & $\begin{array}{l}\text { Transferrin } \\
\text { saturation }\end{array}$ & $\begin{array}{l}\text { Total iron binding } \\
\text { capacity }\end{array}$ & $\begin{array}{l}\text { Ferritin } \\
\text { Serum }\end{array}$ \\
\hline Iron deficiency anemia & $\uparrow$ & $\downarrow$ & $\uparrow$ & $\downarrow$ \\
Anemia of chronic disease & $\leftrightarrow$ or $\uparrow$ & $\downarrow$ & $\downarrow$ & $\downarrow$ \\
HF-related anemia with iron deficiency & $\uparrow$ & $\downarrow$ & $\leftrightarrow$ or $\uparrow$ & $\leftrightarrow$ or $\uparrow$ \\
\hline
\end{tabular}

Abbreviation: HF, heart failure.

of adverse cardiac remodeling, improved exercise tolerance, and improved health-related quality of life, along with a potential for reduced ischemic myocardial damage by inhibition of myocardial apoptosis. ${ }^{42}$ Given the significant risk related to volume overload, blood transfusion is not a first-line therapy, except in patients with severe symptomatic anemia (hemoglobin $<7 \mathrm{~g} / \mathrm{dL}$ ). One may consider oral iron therapy, but gastrointestinal side effects are frequent $(20 \%-30 \%)$, and often result in poor compliance. ${ }^{43,44}$ In addition, a large quantity of oral iron is required for extended periods to replete the iron stores ${ }^{45}$ Consequently, randomized trials of oral iron application in chronic heart failure are lacking.

\section{Intravenous iron therapy}

A number of different intravenous iron agents are commercially available with a low toxicity profile. ${ }^{46} \mathrm{~A}$ trivalent iron $\left[\mathrm{Fe}^{3+}\right.$ or $\left.\mathrm{Fe}(\mathrm{III})\right]$ is released from the core of these colloids $\left[\mathrm{Fe}^{3+}\right.$ or $\left.\mathrm{Fe}(\mathrm{III})\right]$. Considerable variety exists with regard to the carbohydrate shell that surrounds the central iron molecule in each intravenous iron preparation. The anaphylactic reactions to iron preparations seen in the past were not related to iron itself, but rather related to the dextran in the shell. ${ }^{47}$ Hence, dextran-free preparations are a safer and preferred alternative. In the US and across most European countries, three predominant intravenous iron preparations have been marketed until recently, ie, iron hydroxide sucrose, iron gluconate, and iron hydroxide dextran. Recently, additional formulations have been introduced, such as ferumoxytol in the US and ferric carboxymaltose in Europe. ${ }^{48}$ Several new compounds are also in development but have yet to be tested in patients with chronic heart failure. ${ }^{49}$

Bolger et al performed a prospective, uncontrolled, open-label study to evaluate the effects of administration of intravenous iron sucrose in 16 patients with systolic heart failure and hemoglobin $\leq 12 \mathrm{~g} / \mathrm{dL}$ (all with serum ferritin $<400 \mu \mathrm{g} / \mathrm{L}){ }^{42,50}$ Patients with a mean left ventricular ejection fraction of $26 \% \pm 13 \%$ and New York Heart Association (NYHA) class II-III heart failure received an average of $950 \pm 137 \mathrm{mg}$ of intravenous iron sucrose. After a mean follow-up of $92 \pm 6$ days, hemoglobin values increased from
$11.2 \pm 0.7 \mathrm{~g} / \mathrm{dL}$ to $12.6 \pm 1.2 \mathrm{~g} / \mathrm{dL}(P=0.0007)$ and mean ferritin values increased from $87 \mu \mathrm{g} / \mathrm{L}$ to $217 \mu \mathrm{g} / \mathrm{L} .{ }^{50} \mathrm{The}$ first double-blind, randomized, placebo-controlled study was performed by Toblli et al using iron sucrose. ${ }^{51} \mathrm{~A}$ total of 40 anemic patients (hemoglobin $<12.5 \mathrm{~g} / \mathrm{dL}$ in men or $<11.5 \mathrm{~g} / \mathrm{dL}$ in women) with iron deficiency (ferritin $<100 \mu \mathrm{g} / \mathrm{L}$ and/or transferrin saturation $\leq 20 \%$ ) were included and received $200 \mathrm{mg}$ of intravenous iron sucrose or placebo weekly for 5 weeks. After 6 months, hemoglobin increased from $10.3 \pm 0.6 \mathrm{~g} / \mathrm{dL}$ to $11.8 \pm 0.7 \mathrm{~g} / \mathrm{dL}$ in the iron sucrose group, and NYHA class, left ventricular ejection fraction, N-terminal probrain natriuretic peptide, and 6-minute walking distance improved (all $P<0.01$ ). Additionally, the group receiving iron sucrose had fewer hospitalizations $(P<0.01)$. However, no such propensities were noted in the placebo group. In the FERRIC-HF (Ferric Iron Sucrose in Heart Failure) study, a total of 35 patients were enrolled in two European centers (all ferritin 100-300 $\mu \mathrm{g} / \mathrm{L}$ plus transferrin saturation $<20 \%$ or ferritin $<100 \mu \mathrm{g} / \mathrm{L}){ }^{52}$ According to their hemoglobin values at baseline, anemic $(<12.5 \mathrm{~g} / \mathrm{dL})$ and nonanemic (12.5-14.5 g/dL) patients were randomized into two groups in a 2:1 ratio to treatment group (iron sucrose) or control, respectively. This study demonstrated that treatment with iron sucrose resulted in an increase in transferrin saturation $(P<0.0001)$ and serum ferritin $(P<0.0001)$. Interestingly, patients showed improvement in their clinical symptoms, independently of whether anemia was present or not. Iron sucrose was noted to be well tolerated with minimal side effects..$^{52}$ The investigators concluded that, in patients with CHF and functional iron deficiency, intravenous iron is associated with significant improvements in maximal exercise capacity and is accompanied by improved symptoms. The improvements were more pronounced in anemic than in nonanemic patients. The FAIR-HF (Ferinject ${ }^{\circledR}$ Assessment in patients with Iron deficiency and chronic Heart Failure) trial is the largest study of intravenous iron published thus far, in patients with chronic heart failure. ${ }^{53}$ This study enrolled 459 patients with CHF NYHA functional class II (left ventricular ejection fraction $<40 \%$ ) and class III (left ventricular ejection fraction $<45 \%$ ) with iron deficiency 
(ferritin level $<100 \mu \mathrm{g} / \mathrm{L}$ or between 100-299 $\mu \mathrm{g} / \mathrm{L}$, if the transferrin saturation was $<20 \%$ ), and a hemoglobin level of 9.5-13.5 g/dL. Patients were randomly assigned in a 2:1 ratio to receive $200 \mathrm{mg}$ of intravenous iron (ferric carboxymaltose) or saline (placebo).$^{54}$ The primary end points were self-reported Patient Global Assessment and NYHA functional class, both at week 24 . Secondary end points included distance walked in 6 minutes and health-related quality of life. ${ }^{54}$ Using the Patient Global Assessment, 50\% of patients receiving ferric carboxymaltose reported being much or moderately improved, as compared with $28 \%$ of patients receiving placebo (odds ratio for improvement 2.51 ; $95 \%$ confidence interval 1.75-3.61). At week $24,47 \%$ of patients assigned to ferric carboxymaltose had an NYHA class I or II, as compared with $30 \%$ of patients in the placebo group (odds ratio for improvement by one class $2.40 ; 95 \%$ confidence interval 1.55-3.71). ${ }^{53}$ Strikingly, the results were similar in patients with and without anemia. Investigators also noted significant improvements with ferric carboxymaltose in the distance on the 6-minute walk test and quality of life assessments. The rates of death, adverse events, and serious adverse events were similar in the two study groups. It was concluded that treatment with intravenous ferric carboxymaltose in patients with CHF and iron deficiency, with or without anemia, improves symptoms, functional capacity, and quality of life together with an acceptable side effect profile. Collectively, these studies indicate that intravenous iron therapy improves symptom status and quality of life in patients with chronic heart failure with and without anemia. In addition, they elucidated the importance of iron deficiency as a valid and independent therapeutic target. However, the benefit of iron therapy must be weighed against the potential risks, including promoting oxidative stress and iron overload in the setting of heart failure as well as chronic kidney disease. Large-scale, randomized controlled studies are needed to determine the mechanisms of benefit and long-term cardiovascular outcomes associated with supplemental iron therapy in elderly patients with heart failure.

\section{Therapy with erythropoietin and other ESA}

Clinical experience with ESA in the chronic kidney disease population has resulted in a great interest in the potential role of ESA in patients with heart failure. In the early 1990s, blood transfusions was the only effective treatment for anemia in patients with CKD prior to the approval of genetically engineered recombinant human erythropoietin in the US. A number of recommendations have been proposed for the clinical use of ESA in the population with CKD. ${ }^{55}$ The target hemoglobin level in CKD is still a matter of great debate, partly due to the increased risk of cardiovascular events, thromboembolic events, and higher mortality associated with higher target hemoglobin levels in randomized controlled studies. ${ }^{56-59}$ In addition to increased viscosity of blood, various other mechanisms are thought to play a role in increasing thromboembolic risks with ESA therapy ${ }^{60}$ Further, not only did the large randomized studies not show retardation of renal progression with ESA treatment, but there was an increased risk in CREATE (Cardiovascular Reduction Early Anemia Treatment Epoetin beta) or no benefit in the

Table 3 Comparison of the design of CREATE, CHOIR, and TREAT studies ${ }^{42,56}$

\begin{tabular}{|c|c|c|c|c|}
\hline Study & Demographics & Clinical subgroups & Baseline GFR & Intervention \\
\hline Pfeffer et $\mathrm{al}^{59}$ & n: 1287 versus 1355 & CVD: 67.9 & GFR: 34 & Darbepoetin alpha titrated to \\
\hline Heart disease subset & (2636/4044 enrolled had CVD) & CHF: 50.2 & & high (I $3.0 \mathrm{~g} / \mathrm{dL})$ versus low \\
\hline of TREAT multicenter, & male: 46, mean age: 70 & PAD: 31.8 & & $(9.0 \mathrm{~g} / \mathrm{dL}) \mathrm{Hgb}$ target \\
\hline international 29 months & White: 69, Black: 19, Hispanic: 9.3 & RAAS blockers: 77.7 & & \\
\hline Singh et $\mathrm{al}^{58}$ & $\mathrm{n}: 192$ versus 183 & $\mathrm{CHF}$ & GFR: 26.9 versus & Epoetin alpha titrated to high \\
\hline CHF subset of CHOIR & mean age (Hgb I 3.5 group & & 26.0 & (13.5 g/dL) versus low \\
\hline \multirow[t]{4}{*}{36 months } & versus Hgb II.3 group): 70.2 & & & (I I.3 g/dL) Hgb target \\
\hline & versus 69.5 male: 46.4 versus 56.3 & & & \\
\hline & Black: 29.3 versus 27.3 & & & \\
\hline & Hispanic: 9.4 versus 12.0 & & & \\
\hline Drüeke et $\mathrm{al}^{57}$ & $\mathrm{n}: 600$ & CHF: $33 \%$ versus $31 \%$ & GFR: 24.9 versus & Epoetin beta 2000 units \\
\hline Open-label, randomized & Group I: target $\mathrm{Hgb}$ of $13-15$ and & ACEI: $51 \%$ versus $47 \%$ & $24.4 \mathrm{~mL} / \mathrm{min}$ & SQ weekly to achieve target \\
\hline \multirow[t]{3}{*}{ CREATE } & group 2: target Hgb of $10.5-11.5$ & ARB: $19 \%$ versus $22 \%$ & & $\mathrm{Hgb} 13-15$ in group I versus \\
\hline & Mean age: 59.3 versus 58.8 years & & & $10.5-11.5$ in group 2 \\
\hline & Male 57 versus female $5 \mathrm{I}$ & & & \\
\hline
\end{tabular}

Abbreviations: ACEl, angiotensin-converting enzyme inhibitor; ARB, angiotensin receptor blocker; CHF, congestive heart failure; CVD, cardiovascular disease; GFR, glomerular filtration rate; Hgb, hemoglobin; NIH, National Institutes of Health; TSAT, transferrin saturation; CREATE, Cardiovascular Reduction Early Anemia Treatment Epoetin beta; CHOIR, Correction of Hemoglobin Outcomes in Renal Insufficiency; RAAS, renin-angiotensin-aldosterone system; TREAT, Trial to Reduce Cardiovascular Events with Aranesp ${ }^{\circledR}$ Therapy. 
CHOIR (Correction of Hemoglobin Outcomes in Renal Insufficiency) and TREAT (Trial to Reduce Cardiovascular Events with Aranesp ${ }^{\circledR}$ Therapy) studies with regard to renal outcomes after correction of anemia (Table 3). Thus, treatment with ESA in patients with HF and CKD should be initiated with caution.

Over the last few years, a number of studies have been published concerning treatment of anemia in chronic heart failure using epoetin or its analog, darbepoetin alfa. In one such study, 26 anemic patients were randomized to receive epoetin (15,000-30,000 IU per week) or placebo for 3 months. Epoetin was well tolerated by all patients. ${ }^{61}$ In this single-blind, placebo-controlled study, patients in the treatment group showed a significant increase in peak oxygen uptake of $15.5 \%(P<0.05)$, and exercise time increased by $11.4 \%(P=0.004)$. Moreover, the 6-minute walking distance increased by $11.9 \%(P<0.05)$. However, this study had a significant limitation, being a single-center study with a small sample size and single-blind design. ${ }^{61}$

Darbepoetin alfa is recombinant human erythropoietin, and has a molecular weight of 37,100 Daltons and additional carbohydrate chains resulting in a longer half-life, increased biologic activity, and decreased receptor affinity. A broad Phase II trial program of darbepoetin alfa in anemic patients with chronic heart failure was conducted (three trials, $n=525$ ). The first study was of a multicenter, doubleblinded, randomized, placebo-controlled design, in which 41 patients with a left ventricular ejection fraction $\leq 40 \%$ and anemia (hemoglobin 9.0-12.0 g/dL) were included and treated with placebo or darbepoetin alfa $(n=19$, starting dose
$0.75 \mu \mathrm{g} / \mathrm{kg}$, treatment 2-weekly) for 26 weeks. ${ }^{62}$ At the end of the study, the change from baseline in hemoglobin was $2.4 \pm 0.4 \mathrm{~g} / \mathrm{dL}$ versus $0.9 \pm 0.5 \mathrm{~g} / \mathrm{dL}$ for the darbepoetin alfa and placebo groups, respectively. The difference in the mean change between the treatment groups was $1.5 \mathrm{~g} / \mathrm{dL}$ (range $0.5-2.4 \mathrm{~g} / \mathrm{dL}, P=0.005)$. Use of darbepoetin alfa was associated with an improvement in quality of life (by Patient Global Assessment; $P=0.03$ ) and a trend toward improved exercise capacity. However, no statistical difference was noted in the primary end point, which was the change in exercise tolerance from baseline to week 27 as measured by peak oxygen uptake (mL/min/kg body weight). ${ }^{62}$ STAMINA-HeFT (Studies of Anemia in Heart Failure Trial), the largest published study of darbepoetin alfa in anemic patients with chronic heart failure, included 319 patients with symptomatic heart failure, left ventricular ejection fraction $\leq 40 \%$, and hemoglobin $\geq 9.0 \mathrm{~g} / \mathrm{dL}$ and $\leq 12.5 \mathrm{~g} / \mathrm{dL}$. Patients were randomized in a double-blind manner to placebo $(n=157)$ or darbepoetin alfa $(n=162)$ subcutaneously every 2 weeks for one year to achieve a target hemoglobin of $14.0 \mathrm{~g} / \mathrm{dL}$. The primary end point was a change from baseline to week 27 in treadmill exercise time. Secondary end points were change from baseline in NYHA class and quality of life. ${ }^{63}$ At week 27 , darbepoetin alfa treatment increased the median (interquartile range) hemoglobin by $1.8(1.1-2.5) \mathrm{g} / \mathrm{dL}$ compared with the placebo group $(0.3$ $[-0.2-1.0] \mathrm{g} / \mathrm{dL} ; P<0.001)$. In the group being treated with darbepoetin alfa, $85 \%$ achieved two consecutive hemoglobin levels of $14.0 \pm 1.0 \mathrm{~g} / \mathrm{dL}$ during the study period. However, the study failed to show any significant improvement in

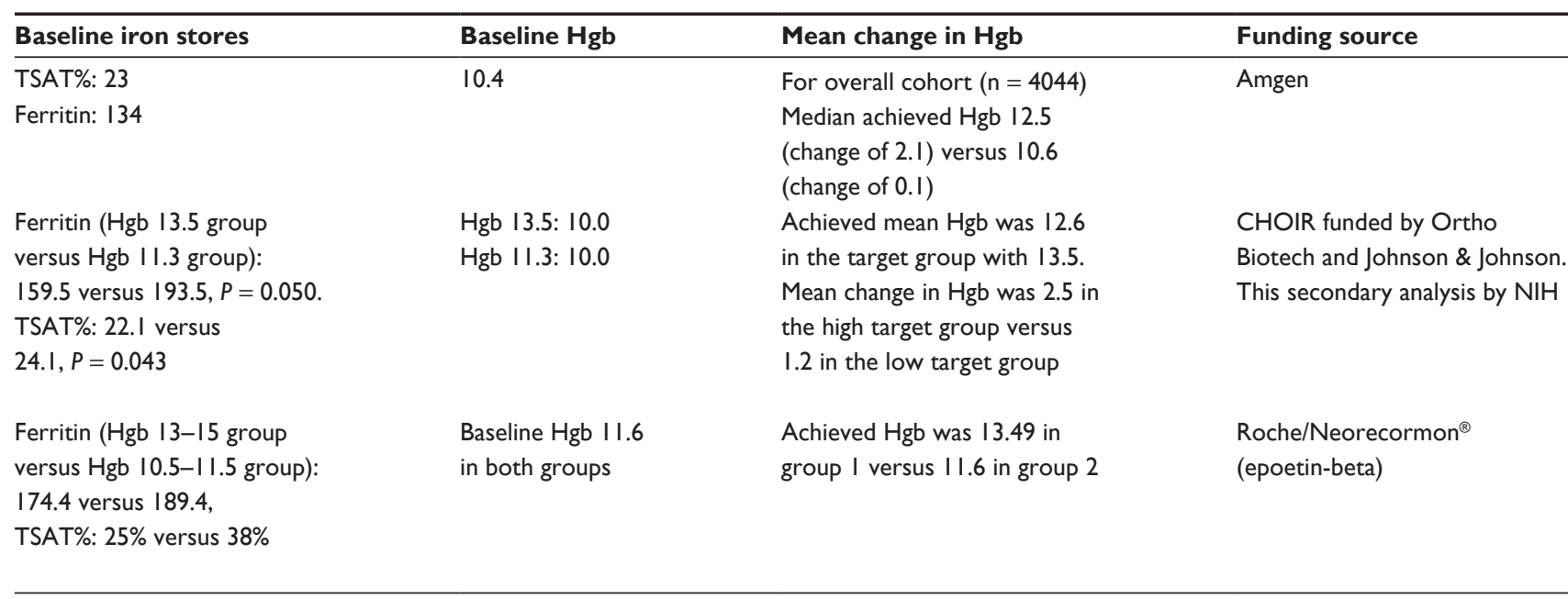




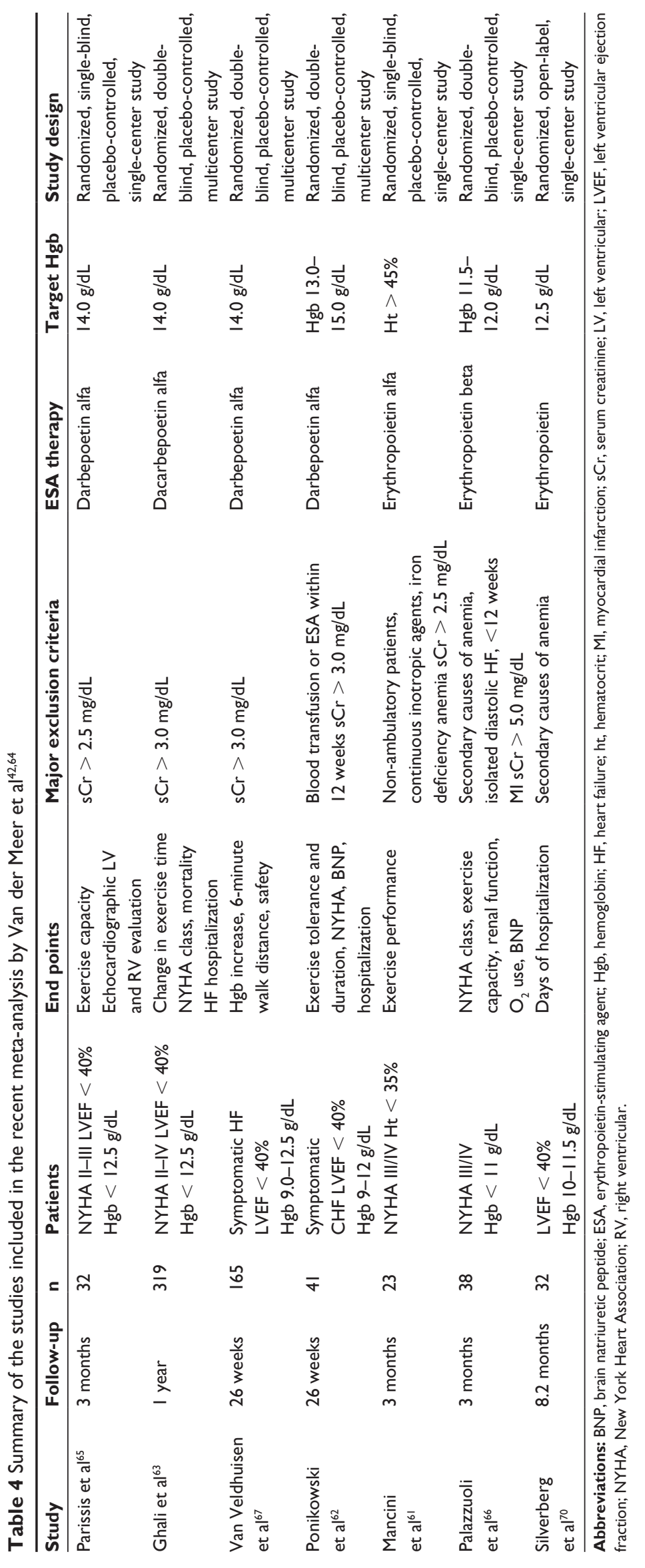


exercise duration, NYHA class, or quality of life score with darbepoetin alfa treatment by intent-to-treat analysis. A trend toward significance was observed with lower risk of all-cause mortality or first heart failure hospitalization in patients treated with darbepoetin alfa compared with placebo, but this was not statistically significant (hazard ratio $0.68 ; 95 \%$ confidence interval $0-1.08 ; P=0.10$ ). Occurrence of adverse events was similar in both treatment groups. ${ }^{63}$

A recent meta-analysis of epoetin treatment in patients with chronic HF considered seven randomized controlled trials comparing ESA treatment with placebo. ${ }^{64}$ Of the 650 patients enrolled, patients treated with ESA $(n=363)$ had a lower risk of hospitalization compared with those treated with placebo $(\mathrm{n}=287)$. A summary of the studies included is shown in Table 4. ${ }^{61-63,65-67,70}$ The treatment did not make any difference to mortality risk, occurrence of hypertension, or venous thrombosis. ${ }^{68}$ Consequently, the RED-HF (Reduction of Events with Darbepoetin Alfa in Heart Failure Trial, clinicaltrials.gov identifier NCT00358215) has been initiated. ${ }^{69}$ The RED-HF trial is a double-blind, randomized, placebo-controlled, parallel-group, multicenter study currently enrolling patients to examine the effect of ESA treatment on morbidity and mortality in patients suffering from heart failure (NYHA class II-IV) with left ventricular ejection fraction $\leq 40 \%$ and anemia. This study of 2600 patients with heart failure and hemoglobin levels of 9-12 g/dL will randomize patients to either placebo or darbepoetin alfa, with a target hemoglobin level of $13 \mathrm{~g} / \mathrm{dL}$. It is the aim to determine, compared with placebo, the efficacy of darbepoetin alfa on the composite of first hospital admission for worsening heart failure or death in subjects with anemia and chronic heart failure. Another study evaluating the impact of treating anemia in subjects with preserved ejection fraction (HFPEF, Anemia in Heart Failure With a Preserved Ejection Fraction study) on functional capacity, ventricular structure and function, along with overall functional status is under way. In this randomized, prospective, double-blind study, 80 subjects with heart failure and preserved ejection fraction will be randomized to either subcutaneous injection of erythropoietin alpha administered weekly using a prespecified dosing algorithm to achieve a target hemoglobin of $13 \mathrm{~g} / \mathrm{dL}$ for 24 weeks versus placebo (NCT00286182). ${ }^{70}$

It is also reasonable to consider combination therapies of epoetin or darbepoetin alfa with intravenous iron, but no data are available from randomized controlled trials in patients with chronic heart failure. ${ }^{46}$ Combined epoetin and intravenous iron therapy was evaluated in a single-center study which included 26 patients with persistent severe congestive heart failure (NYHA class $>$ III), a hemoglobin level of $<12 \mathrm{~g} \%$, and resistance to maximally tolerated congestive heart failure therapy. ${ }^{71}$ Intravenous iron sucrose and subcutaneous epoetin were administered once weekly for 7 months (treatment target hemoglobin $12 \mathrm{~g} / \mathrm{dL}$, serum ferritin $>400 \mu \mathrm{g} / \mathrm{L}$, or transferrin saturation $>40 \%$ ). The mean hemoglobin level improved to $35.9 \% \pm 4.22 \%$, along with improved mean left ventricular ejection fraction to $35 \% \pm 8 \%$, and mean NYHA class improved to $2.7 \pm 0.7$ $(P<0.001)$. However, a small sample size and open-label design were significant limitations of this study. ${ }^{71}$ The same investigators published a randomized open-label study about a year later which included 32 patients with moderate to severe congestive heart failure (NYHA class III-IV) who had a left ventricular ejection fraction $<40 \%$ despite maximally tolerated doses of CHF medications, with hemoglobin levels persistently between $10.0 \mathrm{~g} / \mathrm{dL}$ and $11.5 \mathrm{~g} / \mathrm{dL}$. The patients were randomized into two groups, ie, group A (16 patients) who received subcutaneous epoetin and intravenous iron to increase the level of hemoglobin to at least $12.5 \mathrm{~g} / \mathrm{dL}$ and group B (16 patients) who received no treatment. After 8 months of therapy, an improvement was noted in NYHA class from $3.8 \pm 0.4$ to $2.2 \pm 0.7(P<0.0001)$ and a significant improvement in left ventricular ejection fraction was seen in the treated patients compared with the untreated control group. ${ }^{72}$

Data regarding treatment with intravenous iron with or without ESA therapy is limited in elderly patients with anemia in the setting of heart failure because this group of patients is often excluded from the studies. ${ }^{73}$ One study evaluated 487 consecutive elderly patients with advanced congestive heart failure along with mild-to-moderate chronic kidney disease and anemia. Of the 65 patients who met the inclusion criteria, 27 patients received combination therapy with ESA and intravenous iron sucrose, while 38 patients in the control group received no treatment for anemia. At follow-up (15.3 versus 8.6 months), patients in the intervention group had higher levels of hemoglobin $(13.5 \pm 1.5$ versus $11.3 \pm 1.1$; $P<0.0001)$, better NYHA functional class $(2.0 \pm 0.6$ versus $3.3 \pm 0.5 ; P<0.001)$, and a lower readmission rate $(25.9 \%$ versus $76.3 \% ; P<0.001)$. In the multivariate Cox proportional hazards model, combined therapy was associated with a reduction of the combined end point of all-cause mortality or cardiovascular hospitalization (hazard ratio $0.2,95 \%$ confidence interval [0.1-0.6]; $P<0.001)$. However, the study was conducted in an open-label, nonrandomized fashion, which may have led to a significant bias in interpretation of the results. ${ }^{73}$ 


\section{Conclusion}

Anemia is a frequent occurrence in HF patients and is common in the elderly population. Although the mechanisms involved in the development of anemia in heart failure are multiple, some of which remain to be scientifically proven, the weight of evidence suggests that it is likely due to a complex interaction of underlying iron deficiency, defective epoetin production, epoetin resistance, and activation of the renin-angiotensin-aldosterone system, along with the presence of underlying chronic kidney disease and activation of proinflammatory cytokines. Once considered a complication of heart failure, anemia is now emerging as a potential contributor and therapeutic target in patients with the condition. Although treatment with intravenous iron has shown promising results in recent years, large-scale, multicenter, randomized, controlled trials are long awaited. Available studies have not reported consistent improvement in symptoms or quality of life with epoetin or darbepoetin alfa therapy in HF patients. This may be partly due to unmasking of underlying functional iron deficiency with ESA therapy alone. Combination therapies may provide a reasonable solution, but multicenter, randomized, doubleblind trials are still lacking, particularly in elderly anemic patients with heart failure. In the elderly population with heart failure and anemia, no evidence-based recommendation to use epoetin or darbepoetin alfa can be made at this stage, unless anemia is very severe and CKD is coexisting, so that appropriate CKD guidelines may be applicable. Given the recent evidence linking ESA therapy to achieve high target levels of hemoglobin in anemic patients with CKD to higher mortality and cardiovascular complications, it would be extremely important to be cautious in utilizing this approach when treating anemic patients with heart failure, including the elderly. Whether newer ESA will have different outcomes remains to be explored in this population. Emerging therapies to counteract mediators of anemia in heart failure may alter the treatment of this condition in the future.

\section{Disclosure}

AKA has served Amgen as ad hoc advisor. RS reports no conflicts of interest in this work.

\section{References}

1. Spence RK. The economic burden of anemia in heart failure. Heart Fail Clin. 2010;6:373-383.

2. Tang WH, Yeo PS. Epidemiology of anemia in heart failure. Heart Fail Clin. 2010;6:271-278.

3. Blanc B, Finch CA, Hallberg L, et al. Nutritional anemias. Report of a WHO Scientific Group. WHO Tech Rep Ser. 1968;405:1.
4. Beutler E, Waalen J.The definition of anemia: what is the lower limit of normal of the blood hemoglobin concentration? Blood. 2006;107: 1747-1750.

5. National Kidney Foundation. KDOQI Clinical Practice Guidelines and Clinical Practice Recommendations for Anemia in Chronic Kidney Disease. Am J Kidney Dis. 2006;5:S1-S3.

6. Locatelli F, Aljama P, Barany P, et al. Revised European best practice guidelines for the management of anaemia in patients with chronic renal failure. Nephrol Dial Transplant. 2004;19:Ii1-Ii47.

7. Kidney Disease: Improving Global Outcomes. Clinical practice guideline for anemia in chronic kidney disease. Kidney Int Suppl. 2012;2:288-291.

8. Groenveld HF, Januzzi JL, Damman K, et al. Anemia and mortality in patients with heart failure a systematic review and meta-analysis. $J$ Am Coll Radiol. 2008;52:818-827.

9. Adams KF Jr, Patterson JH, Oren RM, et al. Prospective assessment of the occurrence of anemia in patients with heart failure: results from the Study of Anemia in a Heart Failure Population (STAMINAHFP) Registry. Am Heart J. 2009;157:926-932.

10. Ezekowitz JA, McAlister FA, Armstrong PW. Anemia is common in heart failure and is associated with poor outcomes: insights from a cohort of 12065 patients with new-onset heart failure. Circulation. 2003; 107:223-225.

11. Tanner H, Moschovitis G, Kuster GM, et al. The prevalence of anemia in chronic heart failure. Int J Cardiol. 2002;86:115-121.

12. Komajda M, Anker SD, Charlesworth A, et al. The impact of new onset anemia on morbidity and mortality in chronic heart failure: results from COMET. Eur Heart J. 2006;27:1440-1446.

13. Anand IS, Kuskowski MA, Rector TS, et al. Anemia and change in hemoglobin over time related to mortality and morbidity in patients with chronic heart failure: results from Val-HeFT. Circulation. 2005;112:1121-1127.

14. Androne AS, Katz SD, Lund L, et al. Hemodilution is common in patients with advanced heart failure. Circulation. 2003;107:226-229.

15. Nanas JN, Matsouka C, Karageorgopoulos D, et al. Etiology of anemia in patients with advanced heart failure. $J$ Am Cardiol. 2006; 48:2485-2489.

16. Allen LA, Felker GM, Mehar MR, et al. Validation and potential mechanisms of red cell distribution width as a prognostic marker of heart failure. J Card Fail. 2010;16:230-238.

17. Dec WC. Anemia and iron deficiency- new therapeutic targets in heart failure? N Engl J Med. 2009;361:2475-2477.

18. Weiss G, Goodnough LT. Anemia of chronic disease. N Engl J Med. 2005;352:1011-1023.

19. Testa M, Yeh M, Fanelli R, et al. Circulating levels of cytokines and their endogenous modulators in patients with mild to severe congestive heart failure due to coronary artery disease and hypertension. $\mathrm{J} \mathrm{Am} \mathrm{Coll}$ Cardiol. 1996;28:964-971.

20. Ganz T. Hepcidin: a key regulator of iron metabolism and mediator of anemia of inflammation. Blood. 2003;102:783-788.

21. Anand IS. Anemia and chronic heart failure: implication and treatment options. J Am Coll Cardiol. 2008;52:501-511.

22. Bolger AP, Doehner W, Sharma R, et al. Anaemia in chronic heart failure: the relationship to inflammatory cytokine expression and prognostic importance. Circulation. 2002;106:570-571.

23. Balducci L, Hardy CL, Lyman GH. Hemopoietic reserve in the older cancer patient: clinical and economic considerations. Cancer Control. 2000;7:539-547.

24. Bommer J. Saving erythropoietin by administering L-carnitine? Nephrol Dial Transplant. 1999;14:2819-2821.

25. Opasich C, Cazzola M, Scelsi L, et al. Blunted erythropoietin production and defective iron supply for erythropoiesis as major causes of anaemia in patients with chronic heart failure. Eur Heart J. 2005;26: 2232-2237.

26. Westenbrink BD, Visser FW, Voors AA, et al. Anaemia in chronic heart failure is not only related to impaired renal perfusion and blunted erythropoietin production but to fluid retention as well. Eur Heart J. 2007;28:166-171. 
27. Le Jemtel TH, Arain S. Mediators of anemia in chronic heart failure. Heart Fail Clin. 2010;6:289-293.

28. Vander Meer P, Lipsic E, Westenbrink BD, et al. Levels of hematopoiesis inhibitor $\mathrm{N}$-acetyl-seryl-aspartyl-lysyl-proline partially explain the occurrence of anemia in heart failure. Circulation. 2005;112: 1743-1747.

29. Bernstein KE, Xiao HD, Frenzel K, et al. Six truisms concerning ACE and the renin-angiotensin system educed from the genetic analysis of mice. Circ Res. 2005;96:1135-1144.

30. Alexandrakis MG, Tsirakis G. International Scholarly Research Network. Hematology. 2012.

31. Izaks GJ, Westendorp RG, Knook DL. The definition of anemia in older persons. JAMA. 1999;281:1714-1717.

32. Price EA, Mehra R, Holmes TH, Schrier SL. Anemia in older persons: etiology and evaluation. Blood Cells Mol Dis. 2011;46;159-165.

33. Tang YD, Katz SD. Anemia in chronic heart failure. Prevalence, etiology, clinical correlates and treatment options. Circulation. 2006; 113:2454-2461.

34. Guralnik JM, Ershler WB, Schrier SL, Picozzi VJ. Anemia in the elderly: a public health crisis in hematology. Hematology Am Soc Hematol Educ Program. 2005:528-532.

35. Guralnik JM, Eisenstaedt RS, Klein HG, et al. Prevalence of anemia in persons 65 years and older in the United States: evidence for a high rate of unexplained anemia. Blood. 2004;104:2263-2268.

36. Horwich TB, Foranow GC, Hamilton MA, et al. Anemia is associated with symptoms, greater impairment in functional capacity and a significant increase in mortality in patients with advanced heart failure. J Am Coll Cardiol. 2002;39:1780-1786.

37. Kosiborod M, Curtis JP, Wang Y, et al. Anemia and outcomes in patients with heart failure: a study from the National Heart Care Project. Arch Intern Med. 2005;165:2237-2244.

38. Go AS, Yang J, Ackerson LM, et al. Hemoglobin level, chronic kidney disease, and the risks of death and hospitalization in adults with chronic heart failure. The Anemia in Chronic Heart Failure: Outcomes and Resources Utilization (ANCHOR) study. Circulation. 2006;113: 2713-2723.

39. Nanas JN, Matsouka C, Karageorgopoulos D, et al. Etiology of anemia in patients with advanced heart failure. $J$ Am Coll Cardiol. 2006;48: 2485-2489.

40. Beck SL, Rohde LE, Clausell N. Etiology and management of anemia in patients with heart failure: how much iron is missing? Congest Heart Fail. 2008;14:25-30.

41. Coyne DW, Kapoian T, Suki W, et al. Ferric gluconate is highly efficacious in anemic hemodialysis patients with high serum ferritin and low transferrin saturation: results of the Dialysis Patients' Response to IV Iron with Elevated Ferritin (DRIVE) Study. J Am Soc Nephrol. 2007; 18:975-984.

42. Agarwal AK, Singh A. Therapy with erythropoiesis-stimulating agents and renal and non-renal outcomes. Heart Fail Clin. 2010;6:323-332.

43. Glaspy J, Cavill I. Role of iron in optimizing responses of anemic cancer patients to erythropoietin. Oncology. 1999;13:461-473.

44. MacDougall IC. Strategies for iron supplementation: oral versus intravenous. Kidney Int Suppl. 1999;69:S61-S66.

45. Pasricha SR, Flecknoe-Brown SC, Allen KJ, et al. Diagnosis and management of iron deficiency anaemia: a clinical update. Med J Aust. 2010;193:525-532.

46. Von Haehling S, Anker MS, Jankowska EA, et al. Anemia in chronic heart failure: can we treat? What to treat? Heart Fail Rev. 2012;17: 203-210.

47. Auerbach M, Ballard $\mathrm{H}$. Clinical use of intravenous iron: administration, efficacy, and safety. Hematol Am Soc Hematol Educ Program. 2010: 338-347.

48. Bhandari S. Beyond efficacy and safety - the need for convenient and cost-effective iron therapy in health care. Nephrol Dial Transplant. 2011;4:i14-i19.

49. MacDougall IC, Rossert J, Casadevall N, et al. A peptide-based erythropoietin receptor agonist for pure red-cell aplasia. N Engl J Med. 2009; 361:1848-1855.
50. Bolger AP, Bartlett FR, Penston HS, et al. Intravenous iron alone for the treatment of anemia in patients with chronic heart failure. $J$ Am Coll Cardiol. 2006;48:1225-1227.

51. Toblli JE, Lombraña A, Duarte P, Di Genarro F. Intravenous iron reduces NT-pro-brain natriuretic peptide in anemia patients with chronic heart failure and renal insufficiency. $J$ Am Coll Cardiol. 2007;50:1657-1665

52. Okonko DO, Grzeslo A, Witkowski T, et al. Effect of intravenous iron sucrose on exercise tolerance in anemic and nonanemic patients with symptomatic chronic heart failure and iron deficiency FERRIC-HF: a randomized, controlled, observer-blinded trial. J Am Coll Cardiol. 2008;51:103-112.

53. Anker SD, Comin Colet J, Filippatos G, et al. Ferric carboxymaltose in patients with heart failure and iron deficiency. w Engl J Med. 2009;361:2436-2448.

54. Anker SD, Colet JC, Filippatos G, et al. Rationale and design of Ferinject assessment in patients with IRon deficiency and chronic heart failure (FAIRHF) study: a randomized, placebo-controlled study of intravenous iron supplementation in patients with and without anaemia. Eur J Heart Fail. 2009;11:1084-1091.

55. Eschbach JW. Current concepts of anemia management in chronic renal failure: impact of NKF-DOQI. Semin Nephrol. 2000;20:320-329.

56. Kansagara D, Dyer EAW, Englander H, Freeman M, Kagen D. Treatment of anemia in patients with heart disease: a systematic review. VA-ESP Project 05-225; 2011.

57. Drueke TB, Locatelli F, Clyne N, et al. Normalization of hemoglobin level in patients with chronic kidney disease and anemia. N Engl J Med. 2006;355:2071-2084

58. Singh AK, Szczech L, Tang KL, et al. Correction of anemia with epoetin alfa in chronic kidney disease. N Engl J Med. 2006;355: 2085-2098.

59. Pfeffer MA, Burdmann EA, Chen CY, et al. Atrial of darbepoetin alfa in type 2 diabetes and chronic kidney disease. $N$ Engl J Med. 2009;361: 2019-2032.

60. Dicato M. Venous thromboembolic events and erythropoiesis stimulating agents: an update. Oncologist. 2008;13:11-15.

61. Mancini DM, Katz SD, Lang CC, et al. Effect of erythropoietin on exercise capacity in patients with moderate to severe chronic heart failure. Circulation. 2003;107:294-299.

62. Ponikowski P, Anker SD, Szachniewicz J, et al. Effect of darbepoetin alfa on exercise tolerance in anemic patients with symptomatic chronic heart failure: a randomized, double-blind, placebo-controlled trial. $\mathrm{JAm}$ Coll Cardiol. 2007;49:753-762.

63. Ghali JK, Anand IS, Abraham WT, et al. Study of Anemia in Heart Failure Trial (STAMINA-HeFT) Group. Randomized double-blind trial of darbepoetin alfa in patients with symptomatic heart failure and anemia. Circulation. 2008:117:526-535.

64. Vander Meer P, Groenveld HF, Januzzi JL, et al. Erythropoietin treatment in patients with chronic heart failure: a meta-analysis. Heart. 2009;95:1309-1314.

65. Parissis JT, Kourea K, Panou F, et al. Effects of darbepoetin alpha on right and left ventricular systolic and diastolic function in anemic patients with chronic heart failure secondary to ischemic or idiopathic dilated cardiomyopathy. Am Heart J. 2008;155:751.

66. Palazzuoli A, Silverberg D, Iovine F, et al. Erythropoietin improves anemia exercise tolerance and renal function and reduces B-type natriuretic peptide and hospitalization in patients with heart failure and anemia. Am Heart J. 2006;152:1096.

67. Van Veldhuisen DJ, Dickstein K, Cohen-Solal A, et al. Randomized, double-blind, placebo-controlled study to evaluate the effect of two dosing regimens of darbepoetin alfa in patients with heart failure and anaemia. Eur Heart J. 2007;28:2208-2216.

68. Geisler BP, van Dam RM, Gazelle GS, et al. Risk of bias in metaanalysis on erythropoietin-stimulating agents in heart failure. Heart. 2009;95:1278-1279.

69. McMurray JJ, Anand IS, Diaz R, et al; RED-HF Committees and Investigators. Design of the reduction of events with darbepoetin alfa in heart failure (RED-HF): a phase III, anaemia correction, morbiditymortality trial. Eur J Heart Fail. 2009;11:795-801. 
70. Maurer MS. Efficacy of treating anemia in heart failure with a preserved ejection fraction (HFPEF) on ventricular function, exercise capacity and health status. ClinicalTrials.gov Identifier: NCT00286182.

71. Silverberg DS, Wexler D, Blum M, et al. The use of subcutaneous erythropoietin and intravenous iron for the treatment of the anemia of severe, resistant congestive heart failure improves cardiac and renal function and functional cardiac class, and markedly reduces hospitalizations. J Am Coll Cardiol. 2000;35:1737-1744.

72. Silverberg DS, Wexler D, Sheps D, et al. The effect of correction of mild anemia in severe, resistant congestive heart failure using subcutaneous erythropoietin and intravenous iron: a randomized controlled study. J Am Coll Cardiol. 2001;37:1775-1780.
73. Comín-Colet J, Ruiz S, Cladellas M, Rizzo M, Torres A, Bruguera J. A pilot evaluation of the long-term effect of combined therapy with intravenous iron sucrose and erythropoietin in elderly patients with advanced chronic heart failure and cardiorenal anemia syndrome: influence on neurohormonal activation and clinical outcomes. J Cardiac Fail. 2009;15:727-735.

\section{Publish your work in this journal}

Clinical Interventions in Aging is an international, peer-reviewed journal focusing on evidence-based reports on the value or lack thereof of treatments intended to prevent or delay the onset of maladaptive correlates of aging in human beings. This journal is indexed on PubMed Central, MedLine, the American Chemical Society's 'Chemical Abstracts
Service' (CAS), Scopus and the Elsevier Bibliographic databases. The manuscript management system is completely online and includes a very quick and fair peer-review system, which is all easy to use. Visit http://www.dovepress.com/testimonials.php to read real quotes from published authors.

Submit your manuscript here: http://www.dovepress.com/clinical-interventions-in-aging-journal 